\title{
Towards Effective Values of Teaching Literature to Secondary School Students
}

\author{
Salah Edin Hassan Elobeid Mohamed \\ Qassim University/ Saudi Arabia, Department of English language \\ Supervisor, Dr. Abdulgadir Mohammed Ali \& Dr. Mohammed Tayib Abdullah
}

\begin{abstract}
This study aims to investigate the significant role of literature teaching on secondary school students who study English as a foreign language. The subjects of the study consisted of (100) secondary school students(females). The experiment took place in Omdurman area. The students were chosen from two Sudanese secondary schools in the same area for the academic year $2015 / 2016$. (50) Students out of (100) studied literature for more than six years and the rest (50) students didn't study any literary texts for the same period. A questionnaire was distributed to (30) English teachers, a student test was given to secondary school students and (10) English directors were interviewed for data collection. A statistical analysis was carried out to find out the relation between literature teaching and its role in promoting the students' performance. The data of the study was analyzed by using the statistical package for the social sciences (SPSS). The findings of the study indicated that, there is a positive, statistical significant relation between the study of literature and the standard of the students in English. On the other hand, the students who studied literature scored high marks in a test that contained the same questions and took the same time for both students, compared with those students who didn't study any literary text. That is to say, Literature teaching, affects positively in the acquisition of English language. The study concluded with some recommendations offered to teachers of English language, administrations of secondary schools and for designers of English curricula in order to encourage students to better learning of English through the teaching of literature.
\end{abstract}

Keywords: significant, literature, acquisition of English language, recommendation

\section{Introduction}

The main purpose of this study was to illustrate the importance of literature teaching in the Sudanese secondary schools in particular and in educational centres in general. Four main values are gained when teaching literature. These values concern the thinking, the performance and the experience of students. In this study atest was distributed to two secondary school in Omdurman district. The first school is Idress Secondary School where the students studied literature and the other school is Um Baddah Secondary School where the students didn't study any literary texts.

The study was to investigate the importance of literature by comparing the degrees scoured by the students in both schools. It is an attempt and a contribution in literature teaching and we know that this area has been completely neglected by many educational centres. This study illustrates that literature reading enabled the students to achieve better results in performance tests or in communication situations. The findings of the analysis of the study have confirmed the findings of the previous studies, especially that literary students are better learners in terms of oral communication and performance. It concludes that, the study of literature influences on the students positively to a large extent. The future researches may support or extend the findings concerning the importance of literature on performance, thinking and education of students.

A lot of persons want to learn English especially literature as they can. For some learners, it is only a matter of reading for enjoyment, but many people want to be able to read literature and understand its content in the easiest way accompanied by the utmost sense of enjoyment and pleasure. The aim of this study is to find out how literary competencies of students who learn English literature can be enhanced by literature. The study focuses on the significance of literature and the general outlines.

According to Showalter (2003, p.22)the teaching of literature, for the educationists in the past as well as present, is considered " a way of making people better human beings.".

Literature reading in schools, universities or educational centres inside Sudan and in many other countries witnesses a real neglect and marginalization, especially at secondary schools and in many educational centres. It is noticed that, literature is the most neglected subject. The researcher would like to add something that might attract the attention of the educationists in general and literature teachers in particular to this subject. To tackle the problems and difficulties in learning, more emphasis will be given to literature teaching. We all know the powerful and significant role that literature plays in the promotion of language acquisition. Literature is a useful tool that encourages the students to express their own ideas, feelings and experiences. Literature enriches one's vocabulary and above all educates the whole character linguistically and culturally. The study investigates the sources of the obstacles and difficulties encountered by both teachers and students in literature learning. Some solutions are offered to tackle these difficulties.

\section{Importance of Literature}

As we all know this question should be asked by everyone. The importance of literature cannot be neglected. It is needed from the earliest stages in order to raise studentse awareness of the cultural and social use of the target language. From the first class and when teaching literature, there should be a clear purpose (an intention is supposed to be hidden). Every literary line should reflect a certain 


\section{International Journal of Science and Research (IJSR) \\ ISSN (Online): 2319-7064}

Index Copernicus Value (2013): 6.14 | Impact Factor (2014): 5.611

purpose. The purpose of teaching literature needs to be interpreted according to the reason and the intention behind incorporating literature in the learning syllabus. Studying literature without a clear purpose, is useless and a waste of time.

Yaqoob (2007) pointed to Diyannies view (2002, pp.2-7) on literature. Diyanni thinks that, literature though transports us to the world, created by imagination, yet evokes our emotions of love, sorrow, joy, and pity, and thus enhances our appreciation and understanding of life.

Literature is seen as the main medium in which the students can develop their language without any doubt. The four skills, reading, writing, speaking and listening can be developed in a noticeable way that attracts the attention of the educationists. Studying literature, on the whole, is a mutual and an interaction between the reader and the writer.

The study of literature has always been viewed as something complex and unattainable. This leads to a situation where literature needs to be clarified in its broadest sense to make it more accessible to students in view of the growing interest in the use of literature in language classrooms. As a subject, Widdowson (1975) said that:

"literature has as its principle aim the development of the capacity for individual response to language use. Hence students who are supposed to have already developed awareness to literary discourse can convey unique personal messages."

According to Collie and Slater (1990:3), there are four main reasons which lead a language teacher to use literature in the classroom. These are valuable authentic material, cultural enrichment, language enrichment and personal involvement.

The importance of literature is explained byGillian (1999) as:
"By exposing students to the rich language of the text, we can expand their language awareness, their overall knowledge of how words and grammar can be used. By presenting students with the complex themes in the literary text we can motivate them to reflect imaginatively on their own experience and on that of writers in different societies. By gently encouraging them to make their own interpretations of a text, we can develop their confidence in forming well-reasoned interpretations of the language that they read and hear"

Murat (2005) presented a paper titled "Teaching English Through Literature" and the conclusion of it, Literature is not only a tool for developing the written and oral skills of the students in the target language but also is a window opening into the culture of the target language, building up a cultural competence in students.

\section{Statement of the Problem}

Literature is a very complicated subject and it is generally considered as one of the most difficult subjects to teach.
There is no right or wrong way to teach a literaryclass. There is an intelligent way to teach it. The purpose of Literature teaching is not just to get an answer; it is to learn what is behind the words, and encourage the student to think and give creative answers. The job of the teacher is not to teach the student, it is to lead the student. Literature learning is very crucial for learners and particularly the students and teachers who deal with this area. Many students in Sudan are characterized with the poor knowledge of literature learning. They even ignore its influential impact on learning and behaviour. The study investigates the difficulties faced by both teachers and students when dealing with any literary text in rose or poetry. Some approaches and strategies are used to teach literature and of course the consequences touched in the students ${ }^{\text {ee }}$ knowledge are amazing. Most teachers consider literature as a Separate subject that has nothing to do with language learning.

This assumption is based on the misinterpretation of the concept of language teaching and learning. The fact, however, remains that there are benefits that a language learner can derive from the inclusion of literature in the educational curriculum for language. The introduction of literature in the syllabus creates some difficulties to the students as well as for the teachers. Students have a poor understanding of the literary text. Besides that, they are not familiar with the text as there are no sufficient inputs or exposure to literary text especially the English literature.

The teachers face many problems in delivering their lessons because they do not know the best way to teach literature. Besides that, perhaps they arenet familiar with the literary text itself which makes them need more time to prepare for the lesson. Sometimes, this preparation needs real knowledge and experience for both teachers and students and the task is tough and complicated.

\section{Objectives of the Study}

The main objectives of this study are:-

1) To explain the approaches and the strategies that are used to acquire literary competence.

2) Teachers are to be acquainted with the above mentioned approaches and strategies to indicate their effectiveness in the promotion of language learning.

3) To illustrate the importance and the effect of some values on students.

4) To indicate the main role of literature in:

a) educating the whole person.

b) enhancing self-esteem.

c) developing the sense of criticism and creativity.

d) D-promoting language fluency and acquisition.

5) To clarify the importance of the use of ICT , IT or multimedia material in literature teaching.

\section{Research Questions}

1) Why do teachers teach literature?

2) Does literature reading affect the process of learning?

3) How is literature useful in encouraging persons to acquire a language?

\section{Volume 4 Issue 11, November 2015}




\section{International Journal of Science and Research (IJSR) \\ ISSN (Online): 2319-7064}

Index Copernicus Value (2013): 6.14 | Impact Factor (2014): 5.611

4) What are the problems that the learner faces when dealing with literature and how to tackle them?

5) What are the approaches and strategies used to teach literature?

6) How do teachers use these approaches and strategies inside the classroom?

7) What are the effects and consequences of the implementation of the above mentioned approaches and strategies on literature learners?

8) What is the relation between literature and fluency?

9) Does the readingof literature affect the behaviour of its reader? How?

10) How can teachers use these approaches and strategies to develop the literary competence in Literature Learning inside the classroom?

11) What are the effects of multimedia in teaching literature?

\section{Methodology}

The researcher described the methodology used to conduct this study and he had illustrated and described the way in which he accomplished the study. The first to be discussed are the subjects, the research tools that are used to collect the data, procedures of data collection, validity and reliability of the research tools.

This study includes an overview, research design, detailed descriptions of the population, interviews, the instruments used in the study as well as the procedures of implementing the measurement tools including the pilot study. The validity and reliability of these tools were verified, methods of data analysis were illustrated and the study ended up with a concise conclusion.

\section{Population of the Study}

The population of the study was (100) secondary school students (females) who used to study English for more than six years. They were chosen randomly from two schools that happened to be in Omdurman town.

\section{The Subjects of the Study}

The subjects of the study are divided into two groups: $1 /$ The students who were exposed to literature during the past years were given a written test. They were given 20 minutes to answer all the provided questions. The aims of the written test were the following points:

1- To measure the performance of the students of thinking.

2- To measure the students "vocabulary.

3- To measure the way in which the students write.

The researcher encouraged the students to answer all the questions of the test to see whether the study of literature affected their performance positively or not.

2/The second group, those were the students who weren't exposed to literature during the past years. They were also given the same test to measure the same previous values (performance, thinking and vocabulary). The students of this group were chosen from a secondary school at Omdurman town.
The subjects in the research have been studying English as a second language for more than six years. That is to say, the students had some prior knowledge of English language and they were able to answer the questions of the test. The researcher divided them into two groups according to their knowledge of literature.

A (100) secondary school students were chosen from two schools in different areas. The students who were chosen to conduct this experiment were studying at the $3^{\text {rd }}$ level. All the female students who participated in this study were the same age and level. They were divided into two groups. Fifty students who studied literature and the other fifty ones who didn't were chosen to conduct the experiment. In other words, a literal group consists of (50) Students and another on-literal group consists of the same number of students (50).

The participants share these characteristics:

1) They are the same age and in the same level $\left(3^{\text {rd }}\right.$ secondary school)

2) The same location (Omdurman district in Sudan)

3) They are all Sudanese female students.

\section{Research Tools}

In this study three basic tools were used to collect data and they can be summed up as follows:

1) A written test given to secondary school students.

2) A questionnaire for teachers.

3) An interview with educational directors.

\section{The Test}

The test consists of four questions and each one is highly required to measure one of the four hypotheses in the study. It takes about (20) minutes to be finished. The questions and the vocabulary in this test are suitable and clear for the students to answer.

After the researcher obtained a permission from the two selected schools to test their students of the third level, he prepared a test to measure the objectives of the study. A number of hundred students participated in the experiment. The students were divided equally into two groups. The students who answered the test were males and females. The students from both groups ought to answer a test distributed to them. That is to say, the same test was to be answered by both of them. The first group was chosen from the students who were found to study literature. The second group consisted of (50) students who didn't study literature at all. The researcher informed the students to answer all the questions and to finish the test in twenty minutes time. The students were told the results of the test would be top confidential so as to lessen the fear of failure and the embarrassment that the students might face. They are encouraged to answer the test in a very friendly atmosphere. The total number of the test questions was four to measure performance (passage general understanding), vocabulary, thinking and writing. Twenty marks were given to the test and the atmosphere of the test was comfortable and suitable. After the students finished, the papers were collected and marked. The scores were listed and analyzed. 


\section{International Journal of Science and Research (IJSR) \\ ISSN (Online): 2319-7064}

Index Copernicus Value (2013): 6.14 | Impact Factor (2014): 5.611

\section{The Questionnaire}

The questionnaire was only designed for teachers who teach English at secondary schools. It consists of (20) points and has (5) options that range from "never" to "always". The items were clear and could be easily understood by the participants.

The main purpose of this questionnaire is to investigate the importance of some literary values of teaching literature at Sudanese secondary schools in specific and educational centres in general. (30) Teachers were asked to participate in the questionnaire to measure the success of the study. Four items in the questionnaire were meant to measure one of the hypotheses provided by the researcher. In other words, the points of the questionnaire were mainly designed to serve the purposes behind the study. It is to investigate the teachers ,attitudes towards all the activities, strategies, approaches and values of teaching literature to students in order to promote their performance, thinking and linguistic abilities. The questionnaire was distributed randomly to thirty English teachers from different schools. The researcher was certain that all the items in the questionnaire were chosen by the participants and no variety was left unanswered. All the participants in the questionnaire were thanked by the researcher for their collaboration in completing the experiment. The questionnaire"s data were analyzed statistically to measure the objectives and hypotheses of the study. The items of the questionnaire were reduced from (22) into (20) and the content of it was clarified so that it could be easily understood and answered. Four or three items of the questionnaire were required to measure one of hypotheses of the study. Luckily most of the teachers who participated in the questionnaire expressed a real sense of enthusiasm in answering all the items and this was a real pleasure to the researcher.

The questionnairewhich was given to the secondary school teachers contained (20) items. Each item focused on the impact of literature on students. The questionnaire was only designed for teachers who teach English at secondary schools. It consists of (20) points and has (5) options that range from "never" to "always". The items are clear and can be easily understood by the participants.

The main purpose of this questionnaire is to investigate the importance of some literary values of teaching literature at Sudanese secondary schools in specific and educational centres in general. (30) Teachers were asked to participate in the questionnaire to measure the success of the study. Four items in the questionnaire were meant to measure one of the hypotheses provided by the researcher. In other words, the points of the questionnaire were mainly designed to serve the purposes behind the study. It is to investigate the teachers ,attitudes towards all the activities, strategies, approaches and values of teaching literature to students in order to promote their performance, thinking and linguistic abilities. The questionnaire was distributed randomly to thirty English teachers from different schools. The researcher was certain that all the items in the questionnaire were chosen by the participants and no variety was left unanswered. All the participants in the questionnaire were thanked by the researcher for their collaboration in completing the experiment. The questionnaire"s data were analyzed statistically to measure the objectives and hypotheses of the study.

\section{Teacher's interview}

In his thesis Salih (2014) indicated to the interview as explained by " (Moster and Kalton, 1971; quoted in Bell 1993:91; Cited in Al-Samawi 2000).Tanveer (2007) states that "The rationale behind the use of interview as a data collection tool was that it can provide access to things that cannot be directly observed, such as feelings, thoughts, intentions, or beliefs. (Merriam, 1998: cited in Ohata, 2005:140)" (p.35).The research tool used in collecting the interview's data was a written interview of (4) questions with (10) educational English directors. Their experience in the field of education is more than (10) years. The directors who participated in the interview were told about the aims and objectives of it. They were also told that their participation would be top confidential and will never be used against them. Their participation was meant to enrich the study and would be directed to the purposes of it.

One of the interviewed teachers agreed with the researcher by saying, that literature teaching develops the students ,cognitive and mental skills .He also stated that literature develops reading, analysis skills and widen the vocabulary of the students. He believes that the reading of literature is the only means of enjoyment for those who appreciate it. According to him literature usually deepens human thought, culture and behaviour of the students. All the points mentioned by the interviewed teachers are typically identical with the researcher's own points of view when speaking about the significant role of literature.

Two interviewed teachers agreed with the researcher that, literature reading develops the four skills, broadens the students $^{\text {ee }}$ vocabulary and develops their way of thinking. One of them said that literature helps the students to exchange knowledge and information, Another interviewed teacher believes that literature equips the students with new concepts, ideas about life. That is to say, they will gain new experiences. All teachers agreed that literature plays an effective and a positive role on the promoting the studentse standard. An interviewed teacher clarified the experiences that the students gain when studying literature. He believes that the students will think of all the places they get to visit in reading, people they get to meet, situation they get to experience without leaving their rooms. Without reading about these characters and places, students will never experience new situations and ideas. Another interviewed teacher clarified the experiences that the students gain when studying literature. He believes that the students will think of all the people and places they get to visit in reading without leaving their rooms.

Without reading about these characters and places the students will never experience new situations.

\section{Data Collection Procedures}

Data collection procedures included the collection of questionnaire's data, written interviews with directors and a test was given to secondary school students. 


\section{International Journal of Science and Research (IJSR)}

ISSN (Online): 2319-7064

Index Copernicus Value (2013): 6.14 | Impact Factor (2014): 5.611

\section{Findings of the Study}

In a study by Neranjani (2011, p,23)),she mentioned whatParan (2008) says: "many research studies bring out the benefit of using literature in learning. There is evidence that using literature motivates the students and engages them in learning. It also brings out the importance of the learning task provided by the teacher for the success of language learning and for the success of literary understanding. The scaffolding provided by the teacher in setting up the task and in the process of learning is important".

Tina and .et al( 2007)in a study concluded to the fact that, the importance of literary texts by adopting FakrulAlam"s (2002) point of view, literary texts can prove to be very useful in the language classroom for a variety of reasons.

\section{Findings}

1) The implementation of literature inside the classroom is resulted in better language performance.

2) Literature helps the students to develop creative thinking.

3) Literature plays an important role in bridging the gaps among students to have better understanding for each other.

4) Literature is a useful tool that encourages the students to enrich their experiences.

\section{Recommendations}

Based on the findings of this study and the previous studies, the following recommendations are suggested:

Recommendations for Teachers of English language:

1) Teachers of English language are recommended to encourage their students to learn literature in order to develop their performance especially in the four skills.

2) Teachers of English language should consider their students' linguistic abilities and minimize the amount of difficult vocabulary that their students encounter when studying literature.

3) The usage of suitable teaching methods, approaches, strategies and materials that suit the students in promoting their acquisition of a second language.

4) Teachers are required to modify the difficult literary texts to suit the student"s vocabulary without losing the essence of the original text.

5) Teachers of English language are recommended to help their students discover the beauty and the importance of literature.

6) A teacher of English language is recommended to encourage the students to learn and act literature in classroom without fear or embarrassment.

7) When studying literature, teachers should maintain a comfortable and friendly atmosphere and design interesting activities that encourage students of literature to read, think and act.
Recommendation for administrations of Secondary

Schools:

1) More emphasis on the importance of literature study is needed through the training of teachers of English language how to teach literature in a very effective way.

2) Introducing the academic directors into secondary schools in order to deal with the problems of literature designing and teaching.

3) Many literary books should be available at schools ${ }^{\text {ee }}$ libraries.

\section{Recommendation for designers of English curricula}

Curricula designers should alter curricula to take into consideration that literature should be included for its necessity and importance.

\section{Suggestions for Further Studies}

The following points are suggested for further research:

1) Different strategies and approaches can be conducted to teach literature for foreign students.

2) A great attention should be taken into consideration to tackle the problems that the students face when studying literature.

3) Extra research on the importance of literature in promoting the students"s standard in terms of performance and vocabulary enrichment.

4) Further research is urgently needed to examine the significant role of literature in promoting the standard of the students.(Brumfit and Carter( 1986) says that: "As far as "literary" studies are concerned, students also acquaint themselves with the nature of literary discourses and therefore are studying literature in a very primary and essential sense."

\section{References}

[1] Brumfit, C and Carter, R. Literature and Language Teaching: New York: Oxford University, 1986.

[2] Collie, J. and Slater, S. Literature in the Language Classroom: A Resource Book of Ideas and Activities. Cambridge: CUP, 1990.

[3] Lazar, G . Literature and Language Teaching: A Resource Book for Teacher and Trainers :London: Cambridge University Press, 1993.

[4] Murat .Teaching English Through Literature".Journal of Language and LinguisticStudies, Vol.1, No.1, April 2005.

[5] Neranjani, E. S. English Literary Competence Through Activity Based Literature Learning . University of Colombo-2011.

[6] Salih, A.A.The Impact of Self-Confidence on EFL Sudanese Tertiary Level Students: El-Imam El-Mahdi University, June 2014.

[7] Showalter, E. Teaching Literature. Malden: Blackwell Publishing Ltd., 2003 Teaching Literature in Context: Cambridge University Press 1975

[8] Wang, T. "CooperativeTeachingStudies" . The Journal of Human Resource and Adult Learning, Vol. 3, Num. 2, December 2007.

[9] Widdowson, H. G. Stylistics and the Teaching of Literature: London: Longman. Adrian Barlow 


\section{International Journal of Science and Research (IJSR) \\ ISSN (Online): 2319-7064}

Index Copernicus Value (2013): 6.14 | Impact Factor (2014): 5.611

[10] Yaqoob ,M . Developing Creative Thinking : Cognitive Approach To The Teaching Of English: National University Of Modern Languages , Islamabad, December 2007

\section{Author Profile}

Salah Edin Hassan Elobeid Mohamed, Department of English language, Qassim University/ Saudi Arabia 